\title{
L'abbé Grégoire. Écrits sur les noirs
}

Tome 1; 1789 - 1808; tome 2; 1815 - 1827.Présentation de Rita HermonBelot, Paris, L'Harmattan, 2009, 2 vol. , 226 et 190 p., ISBN 978-2-296-08 179-9 et 978-2-296-08 179-6, 24 et $20,50 €$.

\section{Bernard Gainot}

\section{(2) OpenEdition}

\section{Journals}

Édition électronique

URL : https://journals.openedition.org/ahrf/11830

DOI : $10.4000 /$ ahrf. 11830

ISSN : 1952-403X

Éditeur :

Armand Colin, Société des études robespierristes

Édition imprimée

Date de publication : 1 juin 2010

Pagination : 262-263

ISBN : 978-2-200-92632-8

ISSN : 0003-4436

\section{Référence électronique}

Bernard Gainot, "L'abbé Grégoire. Écrits sur les noirs », Annales historiques de la Révolution française [En ligne], 360 | avril-juin 2010, mis en ligne le 01 juin 2013, consulté le 23 avril 2022. URL : http:// journals.openedition.org/ahrf/11830 ; DOI : https://doi.org/10.4000/ahrf.11830

Ce document a été généré automatiquement le 23 avril 2022

Tous droits réservés 


\section{L'abbé Grégoire. Écrits sur les noirs}

Tome 1; 1789 - 1808; tome 2; 1815 - 1827.Présentation de Rita HermonBelot, Paris, L'Harmattan, 2009, 2 vol. , 226 et 190 p., ISBN 978-2-296-08 179-9 et 978-2-296-08 179-6, 24 et $20,50 €$.

\section{Bernard Gainot}

\section{RÉFÉRENCE}

L'abbé Grégoire. Écrits sur les noirs, Tome 1; 1789 - 1808; tome 2; 1815 - 1827.Présentation de Rita Hermon-Belot, Paris, L'Harmattan, 2009, 2 vol. , 226 et 190 p., ISBN 978-2-296-08 $179-9$ et $978-2-296-08179-6,24$ et $20,50 €$

1 Il s'agit d'un regroupement des principaux ouvrages de Grégoire sur la question de la couleur, la question coloniale, l'évolution de l'État d'Haïti. Les textes sont regroupés par ordre chronologique, avec une présentation de Rita Hermon-Belot, qui fait autorité depuis son beau travail sur l'abbé Grégoire, La politique et la vérité, paru en 2000.

Dans le tome1, nous trouvons le Mémoire en faveur des gens de couleur, de 1789, qui marque l'intervention de Grégoire sur la question de l'égalité raciale, qui restera inscrite à l'horizon de ses combats jusqu'à la fin de sa vie. Ce texte illustre notamment l'infléchissement des positions de la Société des Amis des noirs, de la lutte prioritaire pour une abolition de la traite et une abolition graduelle de l'esclavage vers un combat pour la destruction immédiate de l'édifice ségrégationniste dans les sociétés coloniales. Les deux textes suivants prolongent cette prise de position initiale.

La Notice sur la Sierra-Leone de 1795 est l'orientation prise par le courant abolitionniste français après le décret du 16 pluviôse en II, en faveur d'une " colonisation nouvelle ", c'est-à-dire le projet d'implantation d'établissements en Afrique, reposant sur le travail libre et les transferts culturels et technologiques, destinés à mettre un terme au commerce négrier. À ma connaissance, c'est la première fois que ce texte important est mis à la disposition du public.

4 Les deux textes suivants illustrent l'engagement de Grégoire en faveur d'une régénération du clergé colonial; l'Épitre des évêques réunis (le clergé constitutionnel) aux 
pasteurs et aux fidèles des colonies françaises, de 1798, et l'apologie de Barthélémy de Las Casas, de 1800.

5 La grande pièce de ce premier tome est La littérature des nègres, de 1808, à la fois défense et illustration du courant philanthropique contre ses détracteurs, et manifeste en faveur de la contribution des Africains à la civilisation universelle.

6 Le tome 2 reprend d'abord les ouvrages qui illustrent l'engagement de Grégoire contre la traite, qui connait un nouvel essor avec la Restauration; De la traite et de l'esclavage des noirs et des blancs, de 1815; et Des peines infâmantes à infliger aux négriers, puisque le trafic des esclaves est désormais illégal, au regard d'un droit international qui se cherche (1822). La même année, Grégoire livre une nouvelle pièce de son projet d'écriture d'une grande histoire de l'esclavage, projet qu'il caresse depuis longtemps, mais qu'il ne mènera pas à son terme, avec Observations préliminaires sur une nouvelle édition d'un ouvrage intitulé Histoire du commerce homicide appelé traite des noirs. Les quatre derniers textes concernent plus particulièrement Haïti, et illustrent les relations tumultueuses que l'abbé entretint avec le premier État noir indépendant du continent américain. Grégoire se pose en instituteur moral de la jeune nation dans ses Considérations sur le mariage et le divorce (1823), puis réaffirme fortement ses convictions dans De la liberté de conscience et de culte à Haïti (1824) et De la noblesse de la peau (1826), marquant l'opposition irréductible entre le christianisme et le préjugé de couleur. Enfin, L'épître aux Haïtiens, de 1827, qui clôt la série, et qui se termine par la formule de désenchantement par rapport aux espoirs que Grégoire avait pu placer dans la jeune république noire; « Haïtiens, adieu! ».

7 Ces textes importants auraient peut-être pu être complétés par les échanges épistolaires avec l'abolitionniste anglais Clarkson, où Grégoire rappelle, contre ce qui est, selon lui, la dérive autoritaire du Royaume du Nord de Christophe, son attachement à la forme républicaine de l'État.

8 L'auteur a choisi de placer en annexe les interventions de Grégoire dans les débats à l'Assemblée nationale constituante en mai 1791 autour de l'égalité politique des citoyens de toutes les couleurs, interventions certes très importantes, mais que l'on trouve plus facilement, et qui auraient nécessité une présentation spécifique.

$9 \mathrm{Au}$ total, il faut saluer cette mise à la disposition des lecteurs intéressés par l'abolitionnisme et par la forte personnalité de Grégoire, de textes de référence, dont le rapprochement souligne la constance d'un engagement et la rectitude d'une pensée. 